\title{
Mechanism Study of the Kidney Renal Papillary Cell Carcinoma Proliferation Inhibition and Apoptosis Induction by EZH2
}

\author{
Shubo Wang \\ College of Pharmacy, Jinan University, Guangzhou, China \\ Email: o_kihiro@163.com
}

How to cite this paper: Wang, S.B. (2021) Mechanism Study of the Kidney Renal Papillary Cell Carcinoma Proliferation Inhibi- tion and Apoptosis Induction by EZH2. Journal of Biosciences and Medicines, 9, 1-11. https://doi.org/10.4236/jbm.2021.92001

Received: January 2, 2021

Accepted: February 2, 2021

Published: February 5, 2021

Copyright $\odot 2021$ by author(s) and Scientific Research Publishing Inc. This work is licensed under the Creative Commons Attribution International License (CC BY 4.0).

http://creativecommons.org/licenses/by/4.0/

\section{(c) (i) Open Access}

\begin{abstract}
EZH2 is an important target in a variety of tumors, but its role in KIRP (Kidney renal papillary cell carcinoma) has not yet been proven. The aim of this study was to investigate the role of EZH2 in KIRP patients. And to investigate the KIRP, we used two KIRP cell lines, SKRC39 and ACHN in this study. We used CCK8 assay and colony formation assay to study the effect of EHZ2 small molecule inhibitor EPZ6438 on cancer cell proliferation, we used Trypan Blue cell counting experiments to study the effect of EZH2 on cancer cell apoptosis, and we also used qRT-PCR to study the mechanism of EZH2 on cancer cell proliferation. The results showed that EZH2 was elevated in KIRP patients; inhibition of EZH2 could inhibit the proliferation of cancer cells and induce the apoptosis of cancer cells, which is valuable for the control of KIRP in patients. As for the mechanism, we found that inhibition of EZH2 upregulated P53 expression and thus activated this tumor suppressor gene, indicating why EHZ1 inhibits renal cancer cells.
\end{abstract}

\section{Keywords}

Cancer Cell, Small Molecule Inhibitor, SKRC39, KIRP, EZH2, P53

\section{Introduction}

Renal cancer accounts for $2 \%$ to $3 \%$ of adult malignancies and accounts for $80 \%$ to $90 \%$ of adult renal malignancies. The incidence rates vary from different countries [1]. Overall, the incidence rates in developed countries are higher than those in developing countries. The incidence rates in urban areas are higher than those in rural areas. The incidence rates in males are more than in females. The male-to-female ratio is about 2:1. The onset of renal cancer can be seen in all age 
groups, and the age of onset is mostly in 50 to 70 years old. Kidney renal papillary cell carcinoma (KIRP) is one kind of kidney cancer [2]. The kidneys work by removing waste from the blood. Kidney renal papillary cell carcinoma is the cancer of tubes that filter those waste products from the blood. There are two types of papillary renal cell carcinoma. Type 1 is more common and grows slowly. Type 2 is more aggressive and grows more quickly [3]. KIRP makes up about $15 \%$ of all renal cell carcinoma, which is the most common type of kidney cancer. Renal parenchymal carcinomas are adenocarcinomas derived from tubular epithelial cells; 85\% of them are clear cell carcinomas, and part of them are granular and mixed cell carcinomas [4] [5]. Haemorrhage, necrosis, cystic changes, and calcification are common in disease site. Born within the renal parenchyma, KIRP cell invades, compresses, and destroys the renal pelvis and calyces, progresses outside the renal capsule, forms a vascular thrombus, or metastases to lymph nodes and other organs. The EZH2 gene encodes a histidine $\mathrm{N}$-methyltransferase that is involved in DNA methylation and inhibits transcription of other genes, which also methylates the $\mathrm{H} 3$ lysine at position 27 [6]. The methylation activity of EZH2 promotes the formation of heterochromatin that silences genes and is one component of the PRC2 complex [7]. Mutations or overexpression of EZH2 are associated with a variety of types of cancer, such as breast, prostate, melanoma, and bladder cancer. Because abnormal activation of EZH2 inhibits the normal expression of tumor suppressor genes, inhibition of EZH2 activity slows tumor growth. The role of EZHZ in other tumors has been well studied, but the effect of EZH2 on KIRP has not been studied before [8]. The aim of this study was to investigate whether EPZ6438 could inhibit proliferation and induce cell apoptosis of KIRP cell line. EPZ6438 is an effective, highly selective inhibitor of EZH2 methyltransferase with an $\mathrm{IC}_{50}$ of $9.9 \mathrm{nM}$ and more than 1000-fold higher selectivity for EZH2 than the other 20 human methyltransferases.

\section{Experimental Methods}

\subsection{Cell Lines}

Cells purchased from Daoguan Biotech. SKRC39 and ACHN cells were cultured in DMEM supplemented with $10 \%$ FBS. Cells were kept at $37^{\circ} \mathrm{C}$ in a humidified incubator with $5 \% \mathrm{CO}_{2}$. Cells are passaged regularly to remove mycoplasma.

\subsection{Cell Viability by CCK8}

Cells were counted and adjusted to $4 \times 10^{5}$ cells $/ \mathrm{mL}$, and $50 \mu \mathrm{L} /$ well was plated in 96-well plates, i.e. $2 \times 10^{4}$ cells per well. For the EPZ6438 solution of 5 $\mu \mathrm{mol} / \mathrm{L}^{-1}$, use the medium to perform gradient dilution to get each concentration, add $50 \mu \mathrm{L}$ of the solution per well, set 4 wells per concentration, and set up the negative control group and the blank group. After 68 hours, $20 \mu \mathrm{L}$ of CCK8 solution was added to each well, and the absorbance of the cells was measured at a wavelength of $490 \mathrm{~nm}$ after 4 hours. Absorbance values for all wells were sub- 
tracted from the mean of the blank control to eliminate the impact of background, all data were normalized with the control group, curve fitting using GraphPad Prism 5.0, and 50\% inhibitory concentration $\left(\mathrm{IC}_{50}\right.$ ) was calculated.

\subsection{Soft Agar Colony Forming Experiment}

Cells were counted and adjusted to $2 \times 10^{5}$ cells $/ \mathrm{mL}$, and $4 \mathrm{~mL}$ was plated in 6-well plates. Cells were collected by centrifugation after 24 hours of mixing at each concentration of EPZ6438, the medium was resuspended, and viable cells were counted. $2 \times 10^{4}$ cells were resuspended in $400 \mu \mathrm{LFBS}, 1 \mathrm{~mL}$ of $2 \times \mathrm{DMDM}$ medium was added, $600 \mu \mathrm{L}$ of $0.86 \%$ soft agar was added and mixed well. Place $500 \mu \mathrm{L} /$ well in a 24 -well plate with 4 replicate wells at each concentration. After 30 minutes, the soft agar was completely solidified and incubated in a cell culture chamber for seven days. Colonies with more than 50 cells were counted under a microscope.

\subsection{Western Blot Assay}

Western blot assay was carried out as the methods previously reported. In brief, the whole-cell lysates were prepared in RIPA buffer and sheared RNA and DNA using sonication. Then, the samples were centrifuged in $13,000 \mathrm{rpm}$ for $10 \mathrm{~min}$ to collect the supernatant. For detecting the level of cytochrome $\mathrm{c}$ in the cytosol, cytosolic fraction was prepared in digitonin extraction buffer $(10 \mathrm{mM}$ PIPES, 0.015\% digitonin, $300 \mathrm{mM}$ sucrose, $100 \mathrm{mM} \mathrm{NaCl}, 3 \mathrm{mM} \mathrm{MgCl}$, $5 \mathrm{mM}$ EDTA, 1 $\mathrm{mM}$ phenylmethylsulfonyl fluoride).

\subsection{Real-Time qRT-PCR Analysis}

Total RNA was extracted using RNeasy Mini Kit (QIAGEN), reverse transcription was performed by the use of Maxima First Strand cDNA Synthesis Kit (Thermo Fisher Scientific) and qRT-PCR was carried out on Real-time Thermocycler (CFX96, Bio-Rad) with SYBR Premix Ex Taq II (Takara Biomedical Technology).

\subsection{Apoptosis Assay by Trypan Blue Cell Counting Experiments}

For KIRP cell lines, cells were treated with EPZ6438 for specific time, and after washed with PBS, the proportion of apoptotic cells were measured by Trypan Blue cell counting experiments.

\subsection{Statistical Analysis}

The experiments in this paper comply with the principle of reproducibility of biological experiments. GraphPad Prism 5.0 software was used for plotting and statistical analysis, and the mean \pm SD (Mean $\pm S D$ ) was used for all data. Differences between two or more groups of data were compared using Student's $t$ test and One-way ANOVA, respectively, and were considered statistically different when the p-value was less than 0.05 . 


\section{Result}

\subsection{High Expression of EZH2 in KIRP Patients}

In the TCGA database, the expression of EZH2 was compared in KIRP patients. EZH2 was found to be highly expressed in KIRP patients as shown by Figure1(A). We also compared the expression of EZH2 according to the stage of tumor development, and in patients of different races, as shown in Figure 1(B) and Figure $1(\mathrm{C})$. The results indicate that EZH2 is highly expressed in KIRP patients. TCGA database reference from http://ualcan.path.uab.edu/index.html.

A Expression of EZH2 in KIRP based on Sample types

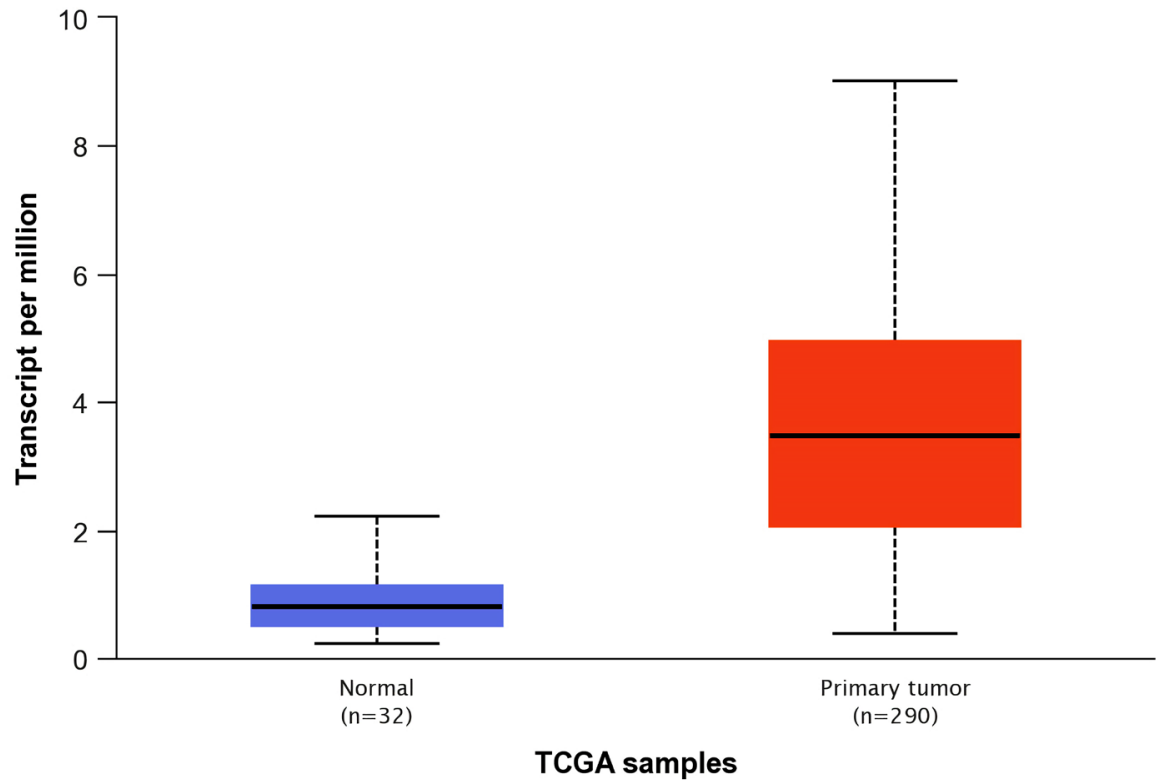

\section{B Expression of EZH2 in KIRP based on individual cancer}

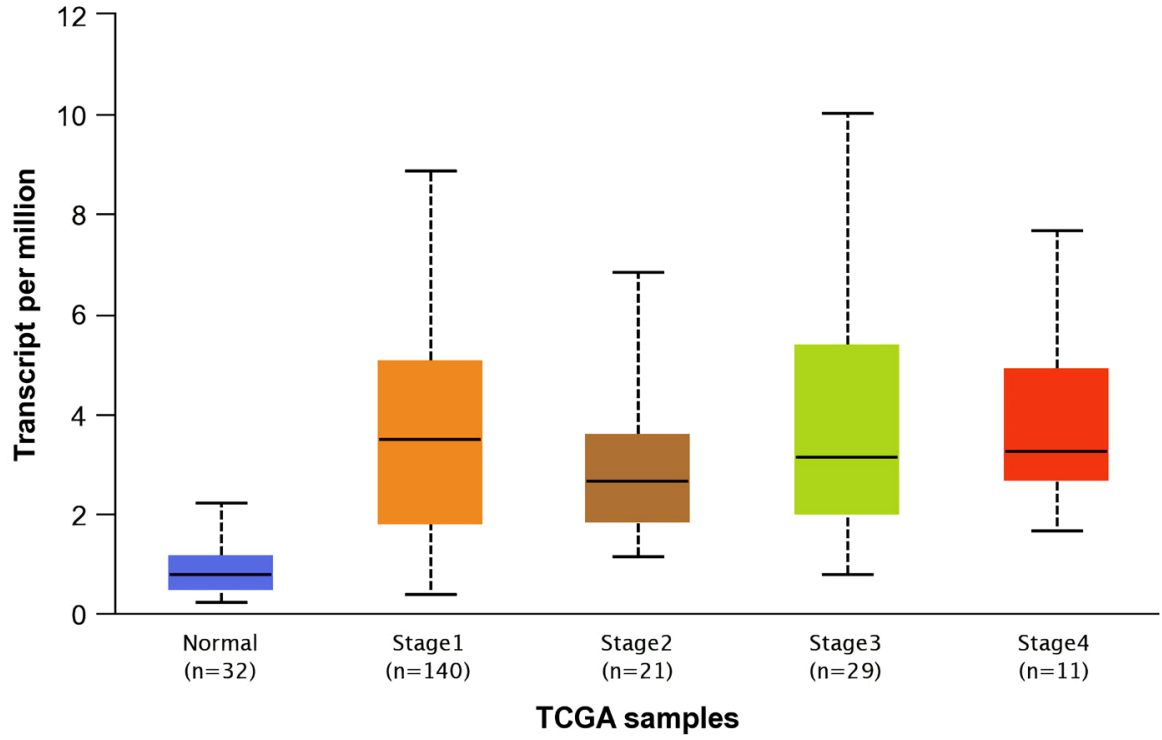




\section{Expression of EZH2 in KIRP based on patient's race}

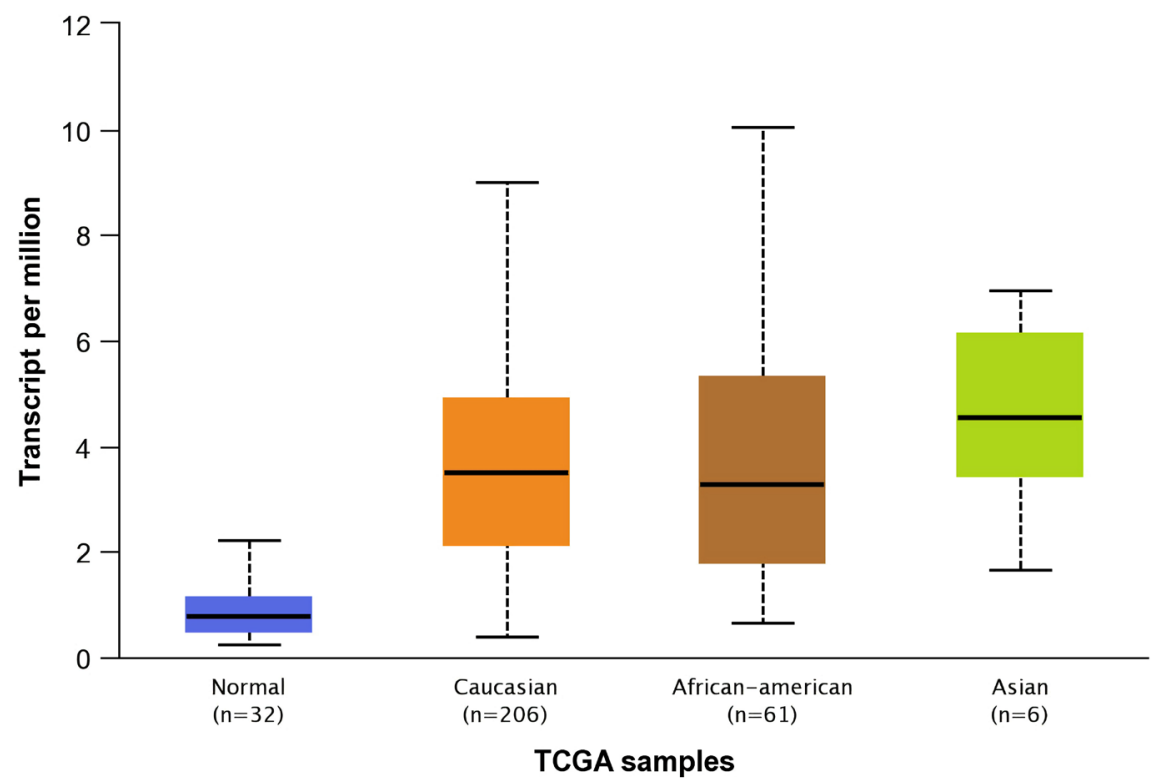

Figure 1. The expression of EZH2 in KIRP patients. (A) EZH2 was overexpressed in KIRP patients; (B) EZH2 was overexpressed in KIRP patients in the different stage of tumor development; (C) EZH2 was overexpressed in KIRP patients in the different races.

\subsection{The Prognosis in KIRP Patients}

Data from patients with EZH2 and KIRP were reviewed in the TCGA database, and patients with KIRP with EZH2 overexpression had a lower survival time than those with low EZH2 expression as shown in Figure 2. This shows that people with low expression of EZH2 have a better prognosis than those with high expression of EZH2. TCGA database reference from http://ualcan.path.uab.edu/index.html.

\subsection{EPZ6438 Significantly Inhibits Viability of KIRP Cells}

As shown in Figure 3, EPZ6438 significantly inhibited the viability of the KIRP cell line, with $\mathrm{IC}_{50}$ values of $15.01 \mu \mathrm{mol} / \mathrm{L}^{-1}$. These results indicate that targeting EZH2 with the small molecule inhibitor EPZ6438 inhibits the activity of KIRP cells.

\subsection{EPZ6438 Significantly Inhibits Proliferation of KIRP Cells}

As shown in Figure 4, KIRP cells treated with $0 \mu \mathrm{mol} / \mathrm{L}^{-1}, 10 \mu \mathrm{mol} / \mathrm{L}^{-1}, 20$ $\mu \mathrm{mol} / \mathrm{L}^{-1}, 30 \mu \mathrm{mol} / \mathrm{L}^{-1}$ of EPZ6438 were subjected to a soft agar cloning experiment, and the number of clones was counted after 7 days and the number of clones significantly decreased with increasing dose of EPZ6438. The results showed that EPZ6438 could significantly inhibit the proliferation of KIRP cells.

\subsection{EPZ6438 Dose-Dependently Induced Apoptosis of KIRP Cells}

As shown in Figure 5, the apoptosis level of KIRP cells treated with $0 \mu \mathrm{mol} / \mathrm{L}^{-1}, 10$ 


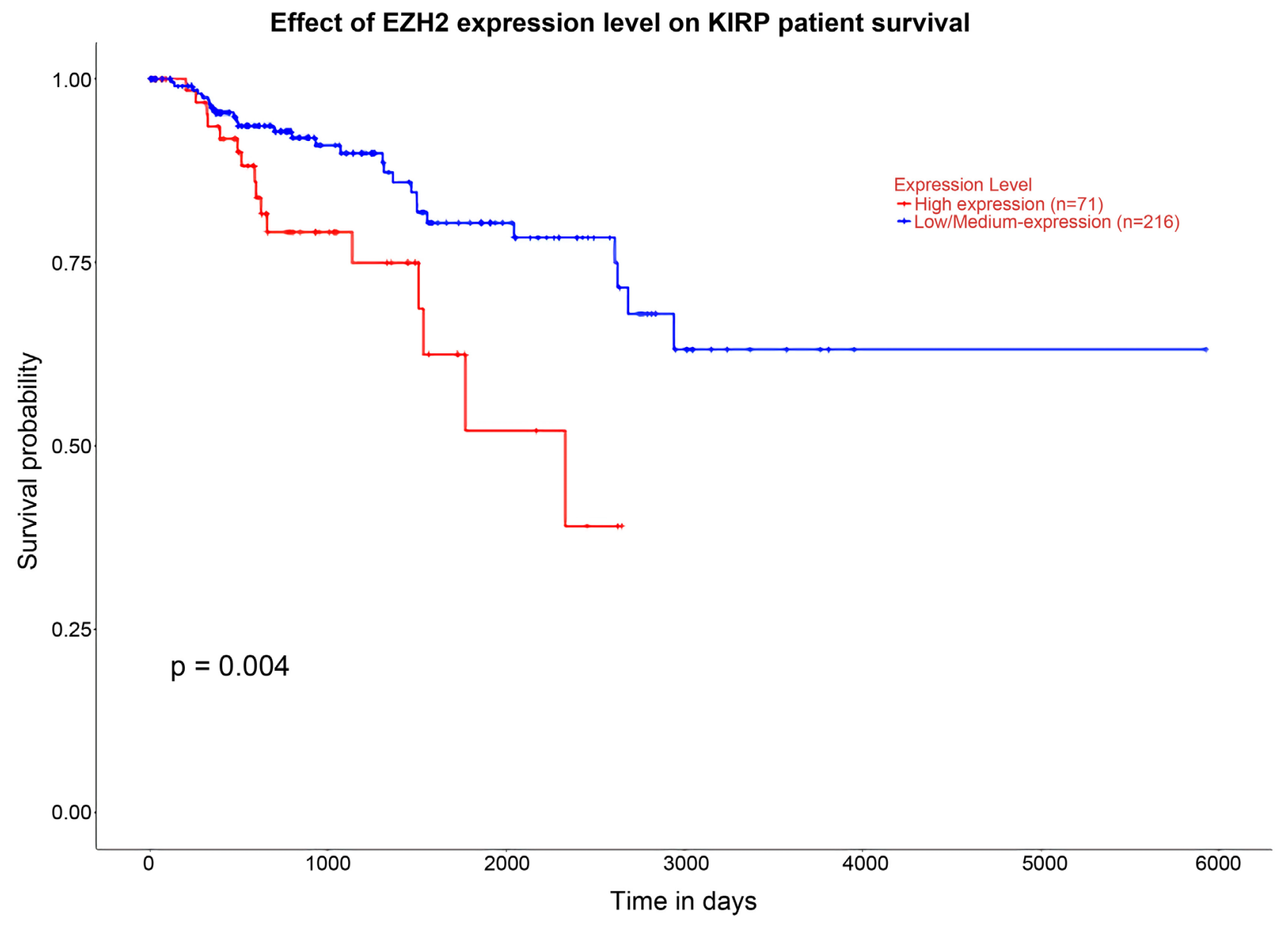

Figure 2. Patients with high expression of EZH2 had a lower survival time than those with low expression.

\section{SKRC39}

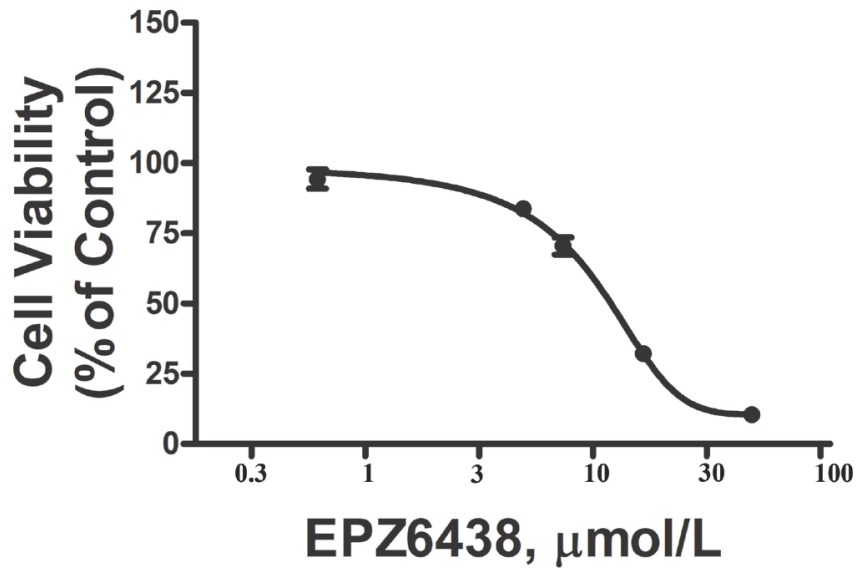

Figure 3. Cell viability of cells is detected by CCK8 assay. IC $_{50}$ of EPZ6438 in SKRC39 cell were $12.01 \mu \mathrm{mol} / \mathrm{L}^{-1}$.

$\mu \mathrm{mol} / \mathrm{L}^{-1}, 20 \mu \mathrm{mol} / \mathrm{L}^{-1}, 30 \mu \mathrm{mol} / \mathrm{L}^{-1} \mathrm{EPZ} 6438$ for 24 hours increased with increasing concentrations of EPZ6438. As shown in Figure 5, EPZ6438 dose-dependently induced apoptosis in KIRP cells. 


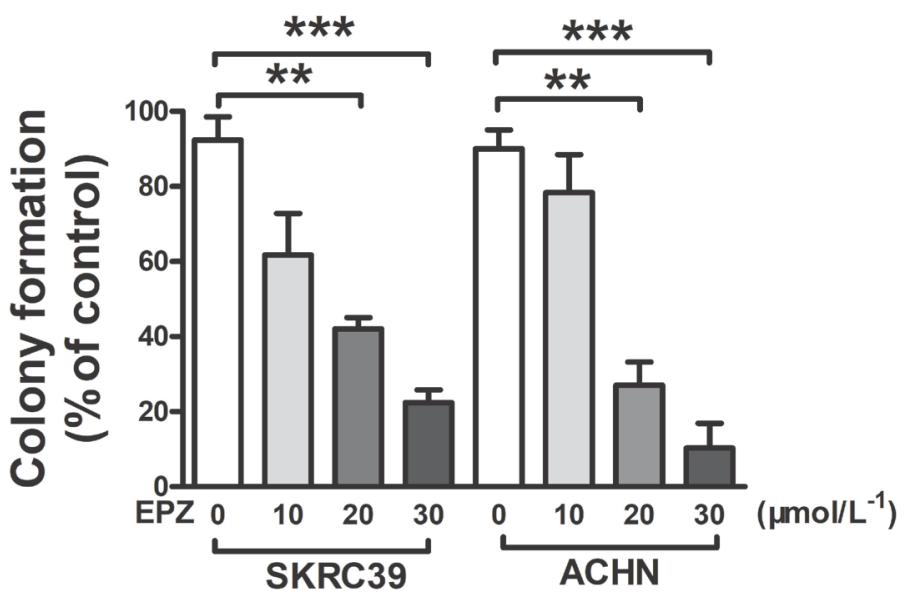

Figure 4. Treatment with EPZ6438 efficiently suppressed cell proliferation. Cell proliferation of SKRC39 and ACHN cell measured by soft agar assay after treatment of EPZ6438.

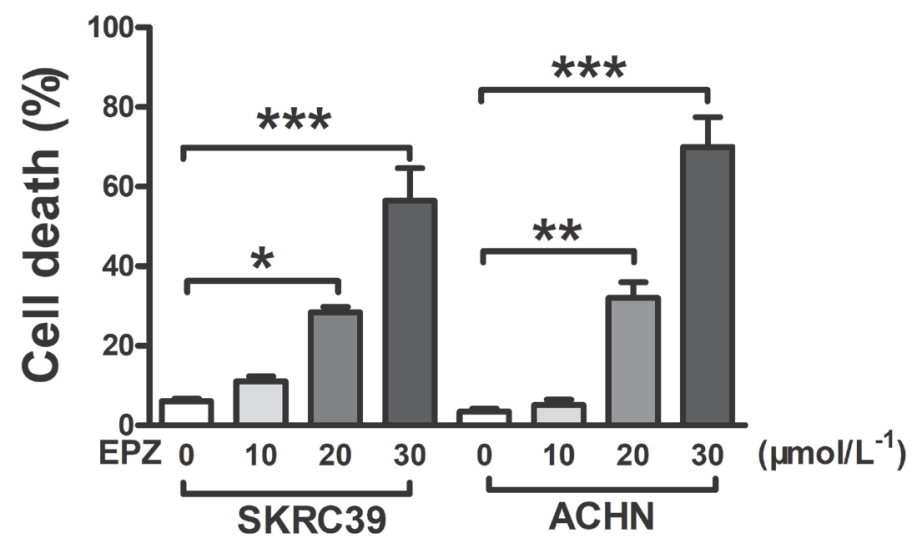

Figure 5. Treatment with EPZ6438 dose-dependently induced apoptosis in KIRP cells. Apoptosis in KIRP cells is detected by Trypan Blue cell counting experiments. $\left({ }^{\star} \mathrm{P} \leq 0.05\right.$, $\left.{ }^{* *} \mathrm{P} \leq 0.01,{ }^{* * *} \mathrm{P} \leq 0.001\right)$

\subsection{EPZ6438 Time-Dependently Induced Apoptosis of KIRP Cells}

As shown in Figure 6, KIRP cells treated with EPZ6438 at $30 \mu \mathrm{mol} / \mathrm{L}^{-1}$ for 0,12 , 18 , and 24 hours showed increased apoptotic levels with increasing treatment time. The results showed that EPZ6438 induced apoptosis of KIRP cells in a time-dependent manner.

\subsection{Mechanism of EPZ6438 Inducing KIRP Apoptosis and Inhibiting KIRP Cell Proliferation}

After treated with 0,15 , and $30 \mu \mathrm{mol} / \mathrm{L}^{-1}$ for 6 hours, the expression of P53 MRNA was increased. The results suggest that the mechanism of EPZ6438 inducing KIRP apoptosis and inhibiting KIRP cell proliferation may be due to the increase of P53 (Figure 7).

\section{Discussion}

The EZH2 gene is a recently identified human novel gene that is involved in cell 


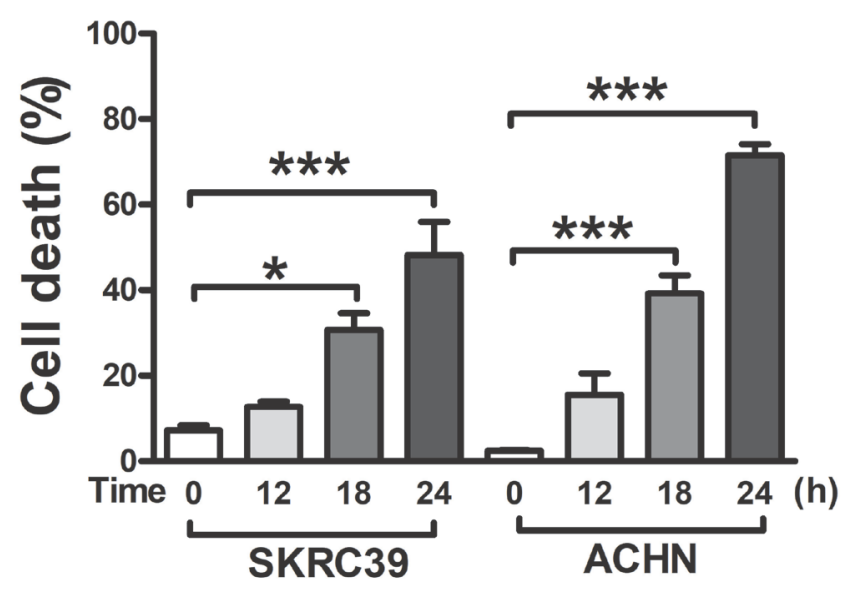

Figure 6. Treatment with EPZ6438 efficiently induced apoptosis in KIRP cells in a time-dependent manner. Apoptosis in KIRP cells is detected by Trypan Blue cell counting experiments. $\left.{ }^{\star} \mathrm{P} \leq 0.05,{ }^{*} \mathrm{P} \leq 0.01,{ }^{* *} \mathrm{P} \leq 0.001\right)$

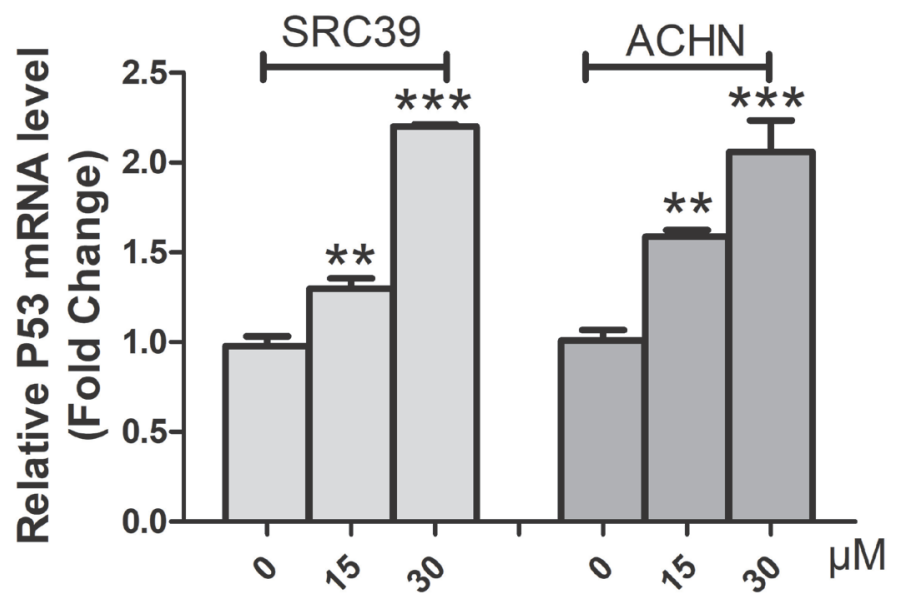

Figure 7. Mechanism of EPZ6438 for inducing KIRP apoptosis and inhibiting KIRP Cell Proliferation.

growth regulation. EZH2 inhibits target genes in chromatin structures, promotes cell proliferation, and its high expression stimulates tumor cell proliferation. This means that it may become a new tumor marker and gradually demonstrate its potential clinical value [9] [10]. A transcriptional memory system that disrupts cells can cause many developmental defects, causing normal cells to lose their own characteristics and become cancerous. EZH2 changes cellular memory and regulates transcription through gene silencing mechanisms, promoting malignant progression of prostate cancer, breast cancer, and lymphoma formation [11]. However, it is unclear whether EZH2 protein is ubiquitous or overexpressed in other tumor cells, what role it plays in the malignant development of other tumors, and its potential clinical value needs further study [12].

The p53 gene is a tumor suppressor gene located on human chromosome $17 \mathrm{p} 13.1$, encoding a $53 \mathrm{kD}$ nuclear phosphorylated protein of 393 amino acids, known as the p53 protein. P53 gene is a negative regulator of cell growth cycle 
and is involved in cell cycle regulation, DNA repair, cell differentiation, apoptosis and other important biological functions [13]. There are two types of p53 gene: Wild type and mutant type, and their products are wild type and mutant type. Wild-type p53 proteins are extremely unstable, have a half-life of only a few minutes, and have trans-activation and broad-spectrum tumour inhibition. Mutant p53 protein stability is increased, half-life is prolonged, and can be detected by immunohistochemistry [14]. P53 mutations (deletions) are common events in human tumors and are associated with the development and development of tumors [15]. P53 overexpression is thought to be associated with tumor metastasis, recurrence, and poor prognosis. P53 can be activated by an enzyme, but scientists have not determined which one. In experiments with human cancer cells, researchers at the University of Medical Dentistry in Tokyo found that "DYRK2" is a "switch" that activates "p53" and then initiates apoptosis. P53 protein plays an important role in the prevention of cancer mechanisms such as apoptosis, genomic stability, and angiogenesis inhibition [16].

In this study, EZH2 was elevated in KIRP patients, and small molecule inhibitors of EZH2 could induce cancer cell apoptosis and inhibit cancer cell proliferation, and the mechanism of this effect was mediated by P53, a tumor suppressor gene. This study demonstrated that EZH2 plays a role in the treatment of KIRP patients and is helpful for future drug development.

\section{Conclusion}

The article shows the role of a new target, EZH2, in the KIRP and the relationship between EZH2 a small molecule inhibitor and the kidney renal papillary cell carcinoma (KIRP). The results have shown that EZH2 can become a potential drug in KIRP patients and should be taken into account in future scientific studies to treat KIRP patients.

\section{Conflicts of Interest}

The author declares no conflicts of interest regarding the publication of this paper.

\section{References}

[1] White, C., Alshaker, H., Cooper, C., Winkler, M. and Pchejetski, D. (2016) The Emerging Role of FTY720 (Fingolimod) in Cancer Treatment. Oncotarget, 7, 23106-23127. https://doi.org/10.18632/oncotarget.7145

[2] Singh, AD., Turell, M.E. and Topham, A.K. (2011) Uveal Melanoma: Trends in Incidence, Treatment, and Survival. Ophthalmology, 118, 1881-1885.

https://doi.org/10.1016/j.ophtha.2011.01.040

[3] Yu, F.X., Luo, J., Mo, J.S., Liu, G., Kim, Y.C., Meng, Z., et al. (2014) Mutant Gq/11 Promote Uveal Melanoma Tumorigenesis by Activating YAP. Cancer Cell, 25, 822-830. https://doi.org/10.1016/j.ccr.2014.04.017

[4] Emmons, M., Rab, R., Sharma, R., Koomen, J. and Smalley, K. (2016) Abstract 294: The Role of the Histone Deacetylase HDAC 8 in Mediating BRAF/MEK Inhibitor 
Metastatic Dissemination and Resistance. Cancer Research, 76, 294-294. https://doi.org/10.1158/1538-7445.AM2016-294

[5] Pollard, T.D. and Borisy, G.G. (2003) Cellular Motility Driven by Assembly and Disassembly of Actin Filaments. Cell, 112, 453-465.

https://doi.org/10.1016/S0092-8674(03)00120-X

[6] Li, X., Peterson, Y.K., Inks, E.S., Himes, R.A., Li, J.Y., Zhang, Y.J., et al. (2018) Class I HDAC Inhibitors Display Different Antitumor Mechanism in Leukemia and Prostatic Cancer Cells Depending on Their p53 Status. Journal of Medicinal Chemistry, 61, 2589-2603. https://doi.org/10.1021/acs.jmedchem.8b00136

[7] Waibel, M., Vervoort, S.J., Kong, I.Y., Heinzel, S., Ramsbottom, K.M., Martin, B.P., et al. (2017) Epigenetic Targeting of Notch1 Driven Transcription Using the HDACi Panobinostat Is a Potential Therapy against T Cell Acute Lymphoblastic Leukemia. Leukemia, 32, 237-241. https://doi.org/10.1038/leu.2017.282

[8] Zhang, W., Zheng, X., Meng, T., You, H., Dong, Y., Xing, J., et al. (2016) HDACI Regulates the PI3K/Akt Signaling Pathway to Reverse MCF-7/PTX Resistance by Inhibiting SET. RSC Advances, 6, 48072-48082.

https://doi.org/10.1039/C6RA06423J

[9] Lang, I., Simone, F., Wyzgol, A., Fick, A., Trebing, J., Antonio Carmona Arana, J., et al. (2015) Binding Studies of TNF Receptor Superfamily (TNFRSF) Receptors on Intact Cells. Journal of Biological Chemistry, 291, 5022-5037. https://doi.org/10.1074/jbc.M115.683946

[10] Sterner, R.M., Kremer, K.N., Amel, D., Westendorf, J.J., van Wijnen, A.J., et al. (2018) Tissue-Nonspecific Alkaline Phosphatase Is Required for MC3T3 Osteoblast-Mediated Protection of Acute Myeloid Leukemia Cells from Apoptosis. The Journal of Immunology, 201, 1086-1096.

https://doi.org/10.4049/jimmunol.1800174

[11] Gilardini Montani, M.S., Granato, M., Santoni, C., Del Porto, P., Merendino, N., D’Orazi, G., et al. (2017) Histone Deacetylase inhibitors VPA and TSA Induce Apoptosis and Autophagy in Pancreatic Cancer Cells. Cellular Oncology, 40, 167-180. https://doi.org/10.1007/s13402-017-0314-Z

[12] Katagiri, H., Nakayama, K., Razia, S., Nakamura, K., Sato, E., Ishibashi, T., et al. (2015) Loss of Autophagy-Related Protein Beclin 1 May Define Poor Prognosis in Ovarian Clear Cell Carcinomas. International Journal of Oncology, 47, 2037-2044. https://doi.org/10.3892/ijo.2015.3191

[13] Zang, J., Liang, X., Huang, Y., Jia, Y., Li, X., Xu, W., et al. (2018) Discovery of Novel Pazopanib-Based HDAC and VEGFR Dual Inhibitors Targeting Cancer Epigenetics and Angiogenesis Simultaneously. Journal of Medicinal Chemistry, 61, 5304-5322. https://doi.org/10.1021/acs.jmedchem.8b00384

[14] Maiti, A., Qi, Q., Peng, X., Yan, L., Takabe, K. and Hait, N.C. (2019) Class I Histone Deacetylase Inhibitor Suppresses Vasculogenic Mimicry by Enhancing the Expression of Tumor Suppressor and Anti-Angiogenesis Genes in Aggressive Human TNBC Cells. International Journal of Oncology, 55, 116-130.

https://doi.org/10.3892/ijo.2019.4796

[15] Chevarie-Davis, M., Riazalhosseini, Y., Arseneault, M., Aprikian, A., Kassouf, W., Tanguay, S., Latour, M. and Brimo, F. (2014) The Morphologic and Immunohistochemical Spectrum of Papillary Renal Cell Carcinoma: Study Including 132 Cases with Pure Type 1 and Type 2 Morphology as Well as Tumors with Overlapping Features. The American Journal of Surgical Pathology, 38, 887-894. https://doi.org/10.1097/PAS.0000000000000247 
[16] Linehan, W.M., Spellman, P.T., Ricketts, C.J., Creighton, C.J., Fei, S.S., Davis, C., Wheeler, D.A., Murray, B.A., Schmidt, L., Vocke, C.D., Peto, M., Al Mamun, A.A., Shinbrot, E., et al. (2016) Comprehensive Molecular Characterization of Papillary Renal-Cell Carcinoma. New England Journal of Medicine, 374, 135-145.

https://doi.org/10.1056/NEJMoa1505917 